\title{
The Capital Stock's Analysis of Industry Transfer in the Western Regions of China: Evidence from Guizhou Province $^{*}$
}

\author{
Hui Zhang ${ }^{1,2}$ \\ ${ }^{1}$ School of Economics, Sichuan University, Chengdu, Sichuan, China \\ ${ }^{2}$ School of Economics, the Northwest University for Nationalities, Lanzhou, Gansu, China \\ 24060565@qq.com
}

\begin{abstract}
The development of China's eastern regions shows the characteristic that the industry transfers to inland in recent years. As the developing areas, the western regions of China must resolve an important question which is effectively undertake the various industries from the eastern regions and continue expands the economic cooperation with the central regions. The capital stock's estimation is the key indicator of analyzing economic growth, and is the premise that can help to undertake the industries for western regions. By introducing the different capital stock estimation's models, the author recalculates the capital stock level of Guizhou Province with different methods, compares and analyses the varied results by different approaches. Therefore, this comparison study can help us to understand the capital stock's level of different regions, and provides some solid basis to undertake the industries transfer from east regions for the west regions of China.
\end{abstract}

Index Terms - Capital Stork, Fixed-capital price index, Inventory, Depreciation, Guizhou

\section{Introduction}

After World War II, in order to solve the problems of economic development in many less developed countries, according to study these different nations, economists put many theories about economic growth. In these theories, almost all of them emphasize the effect of capital in economic growth. Some scholars even believe that the capital is a key factor to decide the economic growth. These thoughts are reflected in "Harold-Domar model", "poverty vicious spiral theory", "big push theory" and " Dual Sector model". Chenery proposes "double gaps model" which is based on the Keynes' national income equilibrium and Harold-Domar growth model, which emphasizes the impact of foreign exchange constraint and savings constraint on the economy. The new classical growth theory as the representative of Solow and the new economic growth theory as the representative of Romer also make a deep analysis on the role of capital. According to these theories, by using the different measurement methods, this paper calculates the Guizhou province's capital stock. This will provide useful theoretical support for western regions to undertake the industries' transfer from the eastern regions of China.

\section{The Method of Estimation the Capital'S Stock}

\subsection{The basic idea}

The capital stock is the capital assets which is installed on a certain number of production units in the certain time, it is generally used to measure the capital investment that put into the process of production, especially is used on the measurement of fixed assets. There are many kinds of methods about the capital stock's calculation, but the basic principle is that the previous actual capital stock and the current actual net investment compose the current actual capital stock. As follows:

$$
K_{t}=K_{t-1}+P N I_{t}
$$

$\mathrm{K}_{\mathrm{t}}$ means the current actual capital stock, $\mathrm{K}_{\mathrm{t}-1}$ means the previous actual capital stock, $\mathrm{RNI}_{\mathrm{t}}$ means the current actual net investment.

$$
R N I_{t}=N I / P I F_{t}=(G I-D S) / P I F_{t}
$$

NI is nominal net investment,GI is the nominal total investment,DS is nominal depreciation, $\mathrm{PIF}_{\mathrm{t}}$ is the price index of fixed assets investment.These two formula combined to get:

$$
K_{t}=K_{t-1}+(G I-D S) / P I F_{t}
$$

In order to analysis the $\mathrm{K}_{\mathrm{t}}$ by using the above formula, We will consider the following variables: $\mathrm{K}_{\mathrm{t}-1}$, GI,DS, $\mathrm{PIF}_{\mathrm{t}}$, as long as we know the specific values of these variables, we can get a time series of the real capital stock.

\subsection{The specific method}

But in the actual measurement of the capital stock, there are different opinions in the details of the scholars. The differences are mainly manifested in the following scholars' opinion:

1) Chow(1993)uses the formula:

$K t=K_{t-1}+$ current year's actual net investment

2) He ju-huang(1992)uses the formula:

$K t=K_{t-1}+$ current year's actual net accumulation

3) Wang xiao-lu \& Fan gang(2000)uses the formula:

\footnotetext{
* This work is supported by the fundamental research funds for the Central Universities Project:" Study on the coordinated development of regional economy with western minority areas and central areas in China"(No:zyz2011017).
} 


\section{$K_{t}(1952$ 's constant prices $)=K_{t-1}(1952$ constant prices $)+$ (current fixed capital formation-depreciation) $/ P_{K}$}

$\mathrm{PK}$ is price index of investment in fixed capital.From the existing research results we can find: the main reason of why measure a specific area's capital stock has different results with above method is how to determine the following several key variables: the capital stock of 1952's, the specific price index selection, the level of investment (depreciation and inventory). This paper discusses these issues and gives the corresponding conclusion.

\section{Several key Problems' Disposal in the Calculation}

\subsection{How to determine the 1952 's capital stock}

1) The basis of calculation

In order to facilitate the analysis, we will show the different results in the table below:

TABLE I the Different Scholars' Capital Stock

\begin{tabular}{|c|c|c|}
\hline Chow & He & Wang \& Fan \\
\hline 1030 & 679 & 1600 \\
\hline
\end{tabular}

Note: 1952's constant prices, unit: 100 million RMB

Data sources: according to the China statistical yearbook 2012 and related documentation.

We can find there are a large difference exists between these conclusions. The question is which one method is more correct when we use it to measure the Guizhou province's capital stock? According to analysis above different methods and results, we find that these three methods have their advantages and disadvantages, and if you fully trust or abandon any kind of method are not suitable. Finally, we make a compromise: because we can't find the best method, then we use each of the method, so we can find a conclusion from the three different results.

2) To determine the specific numerical

Now the new question is: when the capital stock of 1952' is fixed in whole country, how can we decide the Guizhou province's capital stock of 1952 year? By analyse the result we propose: In 1952, the data of national capital stock is calculated from the different province's capital stock data, the formation of capital stock data in anyone province is closely related on the level of local economic development. Therefore, we use the 1952 Guizhou province's GDP in the proportion of whole country's GDP in the same year as the basis, we do the re-measure by using the above methods. The new results in the table below:

TABLE II the Capital Stock of Guizhou

\begin{tabular}{|c|c|c|}
\hline Chow & He & Wang \& Fan \\
\hline 12.98 & 8.56 & 20.16 \\
\hline
\end{tabular}

Note: the Guizhou's GDP is 623 million RMB in 1952; the GDP of China is 67900 million RMB in that year.1952's constant prices, unit: 100 million RMB

Data sources: according to the China, Guizhou statistical yearbook 2012 and related documentation.

\subsection{How to select the price index}

According to comprehensive analyse the different scholars' research, we find there're two kind of price index can be used:

1) Shanghai price index

Zhang Jun \& Zhang yuan(2003) find the fixed capital of Shanghai since 1950 to 2000 and the related index in the appendix of "Yearbook of statistics in Shanghai (2001) ", they give their interpretation by analysing these data. I agree with them. As one of the most developed and the most perfect area of China, the economic development of Shanghai can represent our country economic development's level and speed. Therefore, because the absence of national capital price index, we use the Shanghai's existing price index is reasonable.

\section{2) The GDP price deflator index}

Although the Shanghai price index can reflect the change of the capital stock at certain extent, but this index can't completely reflect the gap between the regions. According to the Shanghai price index can't reflect the price changes completely, I also take a different method to make up this deficiency. It is the GDP price deflator index. The calculation of GDP price deflator index as follows: First, We should collect the Guizhou province's actual value GDP and the GDP price index from 1952 to 2008. Second, we use the GDP in 1952 as the base year unchanged, multiplies the other year's GDP price index and then divides by 100 , so we can get any one year's real GDP which is reflected by the 1952's GDP. Finally, we use the actual GDP of each year divides the any one year's real GDP which is reflected by the 1952's GDP, so we can get the GDP price deflator index what we need.

\subsection{How to calculate the NI}

The key factor in the capital stock is how to calculate the RNIt, and how to determine a more accurate current net investment is the biggest challenge before calculate the RNIt. Because of different understanding about the NI, three scholars' opinions are different. The main reason of this situation is due to the statistical data's uncertainty. For the sake of convenience, the questions about calculate the NI will be summarized as follows:

1) How to understand the meaning of GI

In the above three methods, the key element of understanding the GI is the definition of the total investment, that means how to deal with the inventory. Because this problem can't be reflected in the above three scholars' article, the total investment will be defined as two types: the first way is the total investment is directly represented by current fixed capital formation; the second way is the total investment composes by the current fixed capital and inventory. (Because the gross capital formation=gross fixed capital formation + inventory).

2) How to decide the current fixed capital formation

Because the data of fixed capital formation only have 1985 to 2011, in order to get the data of 1952 to 1984 , we use the data of expenditure approach GDP. Because the mean 
value is very close, so we believe there is a relatively stable tendency between the two data.

3) How to decide the inventory

The processing method of inventory is same as before.

Because the mean value is very close, so we believe there is a relatively stable tendency between the two data.

4) How to decide the depreciation

Because the depreciation has the same problem with fixed capital formation, so we take the same way to deal with: (depreciation of 1990 to2011) / (total investment in fixed assets 1990 to 2011) $\times($ total investment in fixed assets 1952 to 1989).

Because the mean value is very close, so we believe there is a relatively stable tendency between the two data.

3.4 The summary of above methods

Through the above introduction we can find, the different factors can constitute different conclusions. The specific combinations are as follows:

TABLE III the Combination of Methods

\begin{tabular}{|c|c|c|c|c|c|c|c|c|c|c|c|c|}
\hline & \multicolumn{10}{|c|}{ Method } \\
\hline & \multicolumn{10}{|c|}{ Chow } & \multicolumn{1}{|c|}{ He } & \multicolumn{3}{|c|}{ Wang \& Fan } \\
\hline RNIt & (1) & (2) & (3) & $(4)$ & (1) & (2) & (3) & (4) & (1) & (2) & (3) & (4) \\
\hline 1 & $\checkmark$ & $\checkmark$ & & & $\checkmark$ & $\checkmark$ & & & $\checkmark$ & $\checkmark$ & & \\
\hline 2 & & & $\checkmark$ & $\checkmark$ & & & $\checkmark$ & $\checkmark$ & & & $\checkmark$ & $\checkmark$ \\
\hline 3 & $\checkmark$ & & $\checkmark$ & & $\checkmark$ & & $\checkmark$ & & $\checkmark$ & & $\checkmark$ & \\
\hline 4 & & $\checkmark$ & & $\checkmark$ & & $\checkmark$ & & $\checkmark$ & & $\checkmark$ & & $\checkmark$ \\
\hline
\end{tabular}

Note:1 means: Depreciation=current fixed capital formation

2 means: Depreciation=the current fixed capital+inventory

3 means: Shanghai price index

4 means: GDP price deflator index

\section{Results and Conclusions}

\subsection{Results}

Because there are many different methods of calculation and coupled with the use of specific differences of index, the main results show as follows:

TABLE IV the Result of Different Methods

\begin{tabular}{|c|c|c|c|c|c|c|c|c|}
\hline & \multicolumn{7}{|c|}{ year } \\
\hline & & 1952 & 1961 & 1971 & 1981 & 1991 & 2001 & 2011 \\
\hline \multirow{4}{*}{$\mathrm{C}$} & 1 & 12.98 & 41.20 & 129.01 & 255.98 & 529.60 & 1288.35 & 6221.32 \\
\hline & 2 & 12.98 & 52.87 & 159.90 & 324.37 & 679.25 & 1553.46 & 5764.33 \\
\hline & 3 & 12.98 & 34.17 & 78.90 & 139.85 & 263.11 & 632.58 & 3229.14 \\
\hline & 4 & 12.98 & 44.37 & 98.78 & 178.27 & 339.49 & 722.34 & 3076.61 \\
\hline \multirow{4}{*}{$\mathrm{H}$} & 1 & 8.56 & 36.78 & 124.59 & 251.56 & 525.18 & 1283.93 & 5482.42 \\
\hline & 2 & 8.56 & 48.45 & 155.48 & 319.95 & 674.83 & 1549.04 & 6273.19 \\
\hline & 3 & 8.56 & 29.75 & 74.48 & 135.43 & 258.69 & 694.57 & 3142.28 \\
\hline & 4 & 8.56 & 39.95 & 94.36 & 173.85 & 335.07 & 722.65 & 2947.16 \\
\hline \multirow{4}{*}{ W } & 1 & 20.16 & 48.38 & 136.19 & 263.16 & 536.78 & 1295.53 & 6326.57 \\
\hline & 2 & 20.16 & 60.05 & 167.08 & 331.55 & 686.43 & 1560.64 & 7236.83 \\
\hline & 3 & 20.16 & 41.35 & 86.08 & 147.03 & 270.29 & 658.91 & 3369.46 \\
\hline & 4 & 20.16 & 51.55 & 105.96 & 185.45 & 346.67 & 800.53 & 3537.19 \\
\hline
\end{tabular}

Note: C- Chow, H-He, W- Wang \& Fan, unit: 100 million RMB.

Data sources: according to the Guizhou statistical yearbook 2012 and related documentation.

\subsection{Conclusion}

The following conclusions can be drawn: stock

1) PIFt is one of the key factors to decide the capital

All the data are divided into two groups, the data uses the Shanghai index are larger than uses the GDP price deflator index. That means the most important thing on the final result is the selection of index if other conditions are similar.

2) The capital stock of 1952 is the main cause of difference between intergroup results

By specific analysis of each group's results, we will find the gap in the all groups with same number's method is simply due to the capital stock of 1952 which has been determined.

3) How to understanding the NI is another key factor in the calculation

When the capital stock of 1952 and PIFt are determined, the key is how to decide the impact of the net investment; it's used to calculate the inventory in certain year. So, the inventtory becomes the key and influences each method's result when the index is the same.

In conclusion, the capital stock is the important indicator to judge the level of economic growth in the different region. But in the specific calculation, because the researcher chooses different methods, the result will show the deviation. Therefore, when we want to calculate the capital stock in a particular area, the difference among the different methods should be fully considered. Every one of researchers should be based on the research objectives, selects the specific calculation methods carefully and gives corresponding explanation. Only in this way w can get the relative correct capital stock in different regions, and provide useful ideas and suggestions to study the certain regional economic growth and questions of industries transfer.

\section{References}

[1] J. He, "Calculating the capital stock of China," The Journal of Quantitative \& Technical Economics, no.8, pp. 24-27, August 1992.

[2] X. Jin, "Chinese provincial capital stock estimates: 1952-2010," Guangdong Social Science, no.2.pp. 46-55, February 2013.

[3] Z. Li, G. Tang, "The Capital Formation and The Capital Adjustment Model During the China's Transition," Economic Research Journal, no.2.pp. 34-42. February 2003.

[4] X. Wang, G. Fan, P. Liu, "Transformation of Growth Pattern and Growth Sustainability in China," Economic Research Journal, no.1.pp. 4-16. January 2009.

[5] M. Ye, Y. Fang, "Estimation, spatial evolution and contribution composition of the capital stock in China," The Journal of Quantitative \& Technical Economics, no.11.pp. 68-84. November 2012.

[6] J. Zhang, Y. Zhang, "Recalculating the capital stock K of China," Economic Research Journal, no.7.pp. 35-43.July 2003.

[7] W. Wang, G. Fan, Sustainability of China economic growth, $1^{\text {st }}$ ed., Springfield: BEI JING, China, Economic Science Press, 2002, pp.55-64. 